\title{
A Novel 1,3-Stannyl Shift Promoted Intramolecular Cyclizations of $\alpha$-Stannyl Radicals with a Formyl Group
}

\author{
Sheng-Yueh Chang, Yar-Fang Shao, Shu-Fang Chu, Gang-Ting Fan, and \\ Yeun-Min Tsai ${ }^{*}$
}

Department of Chemistry, National Taiwan University, Taipei, Taiwan 106, Republic of China

ymtsai@mail.ch.ntu.edu.tw

Received July 29, 1999

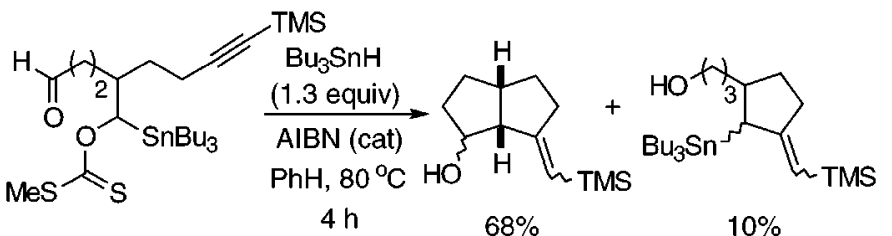

Reactions of $\alpha$-stannyl bromides and xanthates with tributyltin hydride generate $\alpha$-stannyl radicals. Intramolecular cyclizations of these radicals with a formyl group afford $\gamma$-stannyl alkoxy radicals that undergo a 1,3-stannyl shift from carbon to oxygen. The carbon radicals obtained can be trapped inter- or intramolecularly. Approximately, the rates of 5-exo cyclizations of $\alpha$-stannyl radicals with a formyl group and terminal olefin are similar.

Intramolecular radical addition to a carbonyl to give a cyclic alcohol is a potentially useful reaction. ${ }^{1}$ However, this type of cyclizations is reversible, and the reverse reaction is generally faster than the cyclization. ${ }^{2}$ In the cases of acylgermanes, ${ }^{3}$ acylsilanes, ${ }^{1}$ thioesters, ${ }^{4}$ and selenoesters, ${ }^{4}$ intramolecular radical additions to the carbonyl moieties in these compounds are followed by irreversible processes. Therefore, these cyclizations can be stopped at the cyclization side. ${ }^{5}$ Herein, we wish to report the intramolecular cyclization

(1) Chang, S.-Y.; Jiaang, W.-T.; Cherng, C.-D.; Tang, K.-H.; Huang, C.-H.; Tsai, Y.-M. J. Org. Chem. 1997, 62, 9089-9098 and references therein.

(2) (a) Beckwith, A. L. J.; Hay, B. P. J. Am. Chem. Soc. 1989, 111 , 230-234. (b) Beckwith, A. L. J.; Hay, B. P. J. Am. Chem. Soc. 1989, 111, 2674-2681. (c) Beckwith, A. L. J.; Raner, K. D. J. Org. Chem. 1992, 57, 4954-4962.

(3) (a) Curran, D. P.; Liu, H. J. Org. Chem. 1991, 56, 3463-3465. (b) Curran, D. P.; Palovich, M. Synlett 1992, 631-632. (c) Curran, D. P. Diederichsen, U.; Palovich, M. J. Am. Chem. Soc. 1997, 119, 4797-4804. (d) Diederichsen, U.; Curran, D. P. J. Organomet. Chem. 1997, 531, 9-12.

(4) Kim, S.; Jon, S. Y. J. Chem. Soc., Chem. Commun. 1996, 13351336.

(5) For other strategies to drive the equilibrium, see: (a) Hays, D. S. Fu, G. C. J. Org. Chem. 1998, 63, 6375-6381. (b) Kim, S.; Oh, D. H. Synlett 1998, 525-527. (c) Batey, R. A.; MacKay, D. B. Tetrahedron Lett. 1998, 39, 7267-7270. of a formyl group with an $\alpha$-stannyl radical $^{6}$ (eq 1). In this cyclization, a novel homolytic 1,3-stannyl shift from carbon to oxygen ${ }^{7-10}$ serves as the driving force.

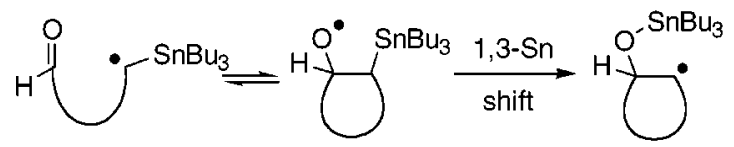

As shown in eq 2, aldehydes $\mathbf{1}^{11}$ were coupled with tributyltin lithium, ${ }^{12}$ and the resulting $\alpha$-stannyl alcohols were

(6) Tsai, Y.-M.; Chang, S.-Y. J. Chem. Soc., Chem. Commun. 1995, $981-$ 982.

(7) For homolytic 1,5-stannyl shift from carbon to oxygen, see: (a) Kim S.; Lee, S.; Koh, J. S. J. Am. Chem. Soc. 1991, 113, 5106-5107. (b) Kim, S.; Lim, K. M. Tetrahedron Lett. 1993, 34, 4851-4854.

(8) For homolytic 1,6-stannyl shift from carbon to oxygen, see: (a) Kim, S.; Lim, K. M. J. Chem. Soc., Chem. Commun. 1993, 1152-1153. (b) Kim, S.; Do, J. Y.; Lim, K. M. Chem. Lett. 1996, 669-670.

(9) For homolytic 1,4-stannyl shift from oxygen to oxygen, see: Alberti, A.; Hudson, A. Chem. Phy. Lett. 1977, 48, 331-333.

(10) For homolytic 1,5-stannyl shift from oxygen to oxygen, see: Davies,

A. G.; Tse, M.-W. J. Organomet. Chem. 1978, 155, 25-30.

(11) Konosu, T.; Oida, S. Chem. Pharm. Bull. 1993, 41, 1012-1018.

(12) Still, W. C. J. Am. Chem. Soc. 1978, 100, 1481-1487. 


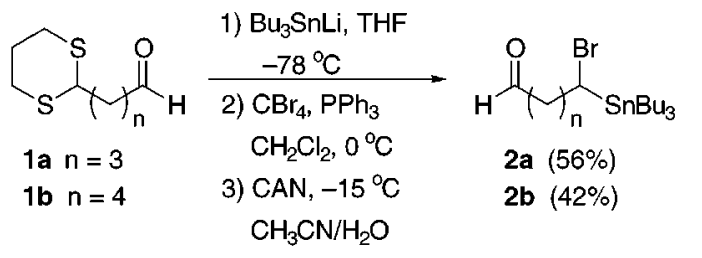

converted to $\alpha$-stannyl bromides using carbon tetrabromide and triphenylphosphine. ${ }^{13}$ The dithiane moiety was then deprotected ${ }^{14}$ to give aldehydes 2 in mild yields over three steps. Treatment of aldehyde $\mathbf{2 a}$ with tributyltin hydride ${ }^{15}$ (Scheme 1) followed by quenching the reaction with benzoyl

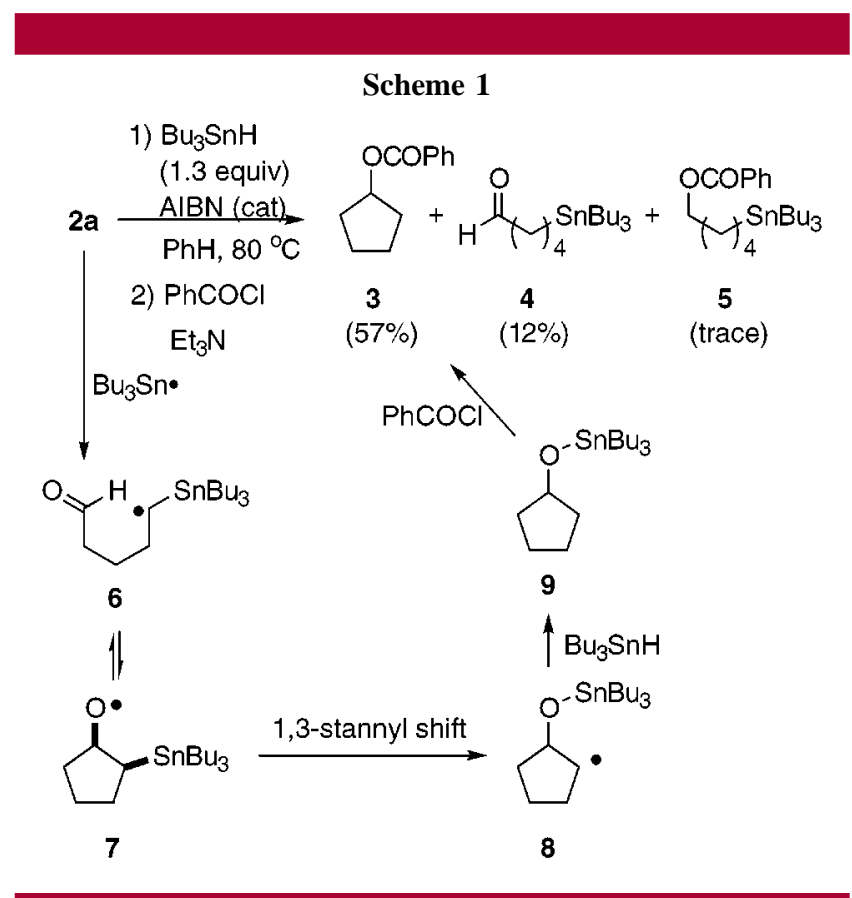

chloride gave cyclopentyl benzoate (3) in 57\% yield. Uncyclized reduction product aldehyde $\mathbf{4}$ was also isolated in $12 \%$ yield along with a trace amount of benzoate $\mathbf{5}$. Benzoate $\mathbf{5}$ was presumably derived from over-reduction of aldehyde 4 by excess tributyltin hydride followed by benzoate formation.

Mechanistically, this cyclization reaction occurs through formation of $\alpha$-stannyl radical 6 first. This radical then cyclizes with the formyl group to generate $\gamma$-stannyl alkoxy radical 7. Because radical cyclizations of carbonyl compounds are generally reversible ${ }^{2}$ it is likely that the oxygen radical and stannyl group may have a chance to adopt a synrelationship as shown in 7 . Alkoxy radical 7 presumably undergoes a 1,3-stannyl shift from carbon to oxygen to generate carbon radical $\mathbf{8}$. It is known that the $\mathrm{O}-\mathrm{Sn}$ bond

(13) Torisawa, Y.; Shibasaki, M.; Ikegami, S. Tetrahedron Lett. 1981, $22,2397-2400$.

(14) (a) Ho, T.-L.; Ho, H. C.; Wong, C. M. J. Chem. Soc., Chem. Commun. 1972, 791-791. (b) Ho, H. C.; Ho, T.-L.; Wong, C. M. Can. J. Chem. 1972, 50, 2718-2721.

(15) The cyclization reaction was performed by slow addition $(4 \mathrm{~h})$ via syringe pump of a benzene solution of tributyltin hydride ( 1.3 equiv, 0.13 $\mathrm{M}$ in benzene) and AIBN ( 0.05 equiv) to a solution of the bromide $(0.1 \mathrm{M})$ in refluxing benzene.
Scheme 2

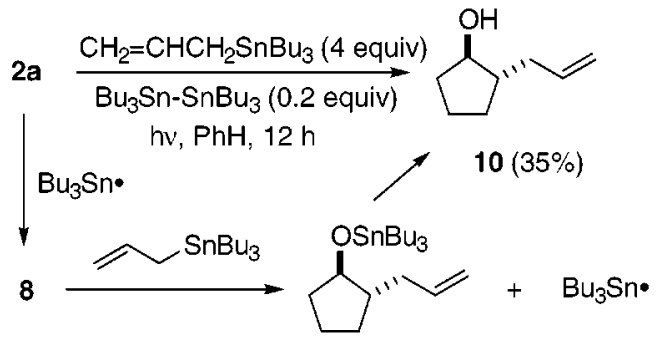

is stronger than the $\mathrm{C}-\mathrm{Sn}$ bond by about $25 \mathrm{kcal} / \mathrm{mol} .{ }^{16}$ This big difference provides a strong thermodynamic driving force to trap alkoxy radical 7. Abstraction of hydrogen from tributyltin hydride by radical $\mathbf{8}$ gives stannyl ether $\mathbf{9}$. The oxygen atom in stannyl ethers is known to be quite nucleophilic. ${ }^{17}$ Therefore, for the convenience of isolation and identification, stannyl ether $\mathbf{9}$ was converted directly to the corresponding benzoate 3 .

When aldehyde 2a (Scheme 2) was treated with allyltributyltin (4 equiv) in the presence of hexabutylditin $(0.2$ equiv) and initiated by photolysis of long wavelength UV light $^{18}(12 \mathrm{~h})$, we were able to isolate alcohol $\mathbf{1 0}^{19}$ in $35 \%$ yield. This reaction provided evidence that indeed radical $\mathbf{8}$ was formed. In the case of 6-exo cyclization (eq 3), aldehyde 2b reacted with tributyltin hydride ${ }^{15}$ and gave $27 \%$ of cyclohexanol (11), 29\% of uncyclized reduction product aldehyde 12, and 9\% of over-reduction product alcohol 13 . The problem of this reaction was revealed by the reaction of aldehyde $\mathbf{2 b}$ with allyltributyltin (eq 4). Along with alcohol $\mathbf{1 4} 4^{20}(10 \%)$, we obtained a $50 \%$ yield of aldehyde $\mathbf{1 5}$ that contains an allyl group at the $\alpha$-position of the carbonyl group. This result indicates that a 1,5-hydrogen transfer ${ }^{21}$ occurs after generation of the $\alpha$-stannyl radical from aldehyde $\mathbf{2 b}$. This process leads to formation of an $\alpha$-carbonyl radical. The $\alpha$-carbonyl radical is then trapped by allyltributyltin to give aldehyde 15.
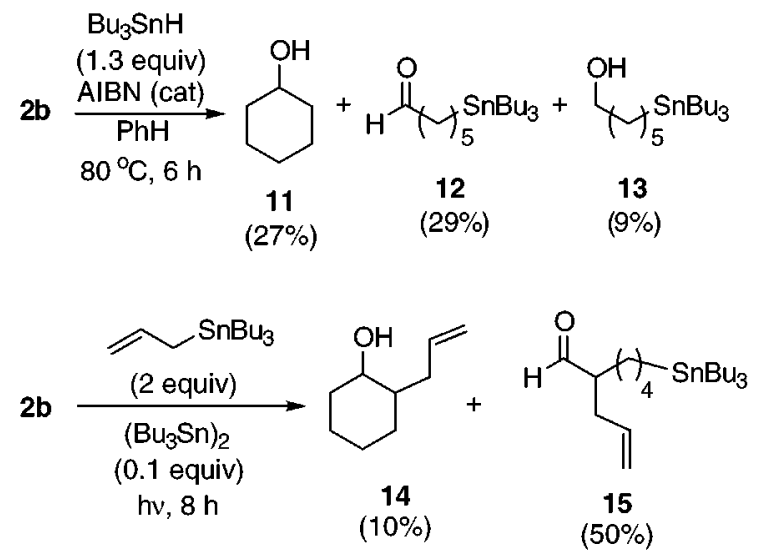

This stannyl shift that promotes the radical cyclization reaction can be employed in a tandem cyclization mode. Instead of using $\alpha$-stannyl bromides, we synthesized xanthates $\mathbf{1 6}$ and $\mathbf{1 7}$ for our studies. ${ }^{6}$ The reaction of xanthate 
<smiles>C=CCCC(CCC=O)C(OC(=S)CCCCCCCCCCCC)SCCCC</smiles><smiles>CC#CCCC(CCCCC)C(CCC=O)OC(=S)SC</smiles>

16 with tributyltin hydride ${ }^{15}$ (eq 5) gave monocyclic aldehyde 18 in $33 \%$ yield. This aldehyde was derived from the addition of an $\alpha$-stannyl radical to the olefin first. Alcohol $19(5 \%)$ was also obtained. This material was presumably derived from reduction of aldehyde $\mathbf{1 8}$ by excess tributyltin hydride. Bicyclic alcohol 20 was isolated in $29 \%$ yield. Small amounts of the benzoate derived from bicyclic alcohol 21 were detected in $4 \%$ yield through benzoylation of the crude cyclization mixture. The benzoates derived from alcohols 20 and 21 thus obtained are identical to that reported by Wilcox et al. ${ }^{22}$ The stereochemistry of alcohols $\mathbf{2 0}$ and $\mathbf{2 1}$

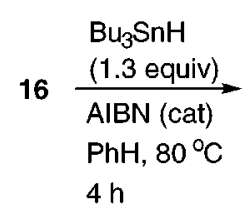<smiles>CCCCCC1CCC(C)C1[SnH2]CCCC</smiles>

$18(33 \%)$

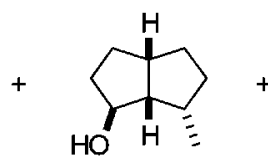

$20(29 \%)$<smiles>CCCCC1CCC(C)C1[SnH2]</smiles>

$19(5 \%)$

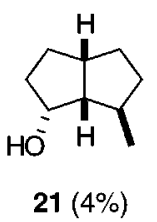

can therefore be determined. There appeared to be other stereoisomers of the alcohols $\mathbf{2 0}$ and $\mathbf{2 1}$; however, the amount was very small and we were not able to identify these minor isomers. Bicyclic alcohols $\mathbf{2 0}$ and $\mathbf{2 1}$ are tandem cyclization products derived from the addition of $\alpha$-stannyl radical 22 (Scheme 3) to the formyl group first. The cyclization

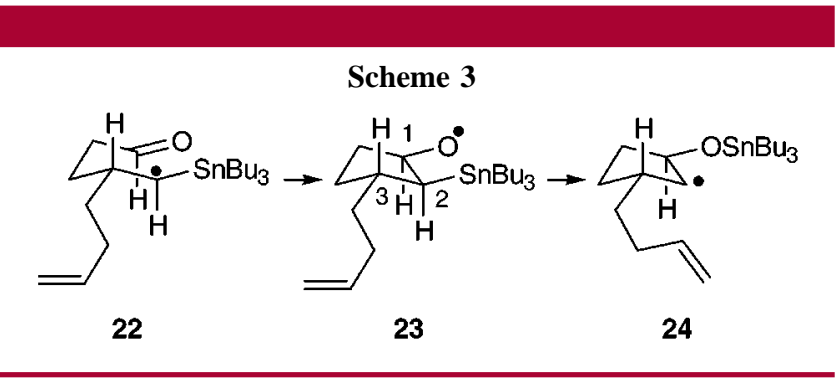

presumably prefers to adopt a chair transition state ${ }^{23}$ with the large groups located at the equatorial position as shown in 22. This leads to the formation of the alkoxy radical $\mathbf{2 3}$ with a predominant trans-1,3-relationship. The stannyl shift

(16) Jackson, R. A. J. Organomet. Chem. 1979, 166, 17-19

(17) Pereyre, M.; Quintard, J.-P.; Rahm, A. Tin in Organic Synthesis; Butterworths: London, 1997; Chapter 11, p 261. used.

(18) A Rayonet photochemical reactor equipped with $3500 \AA$ lamps was

Org. Lett., Vol. 1, No. 6, 1999 of alkoxy radical $\mathbf{2 3}$ gives radical $\mathbf{2 4}$. This radical cyclizes with the olefin to give bicyclic alcohol $\mathbf{2 0}$ as the major isomer with known endo-selectivity. ${ }^{24}$

The rates for the addition of an $\alpha$-stannyl radical to an olefin and a formyl group appear to be similar because the total yield of monocyclic products $\mathbf{1 8}$ and $\mathbf{1 9}$ is close to that of bicyclic alcohols 20 and 21. With this information available, it is possible to attenuate the tandem system to favor the bicyclic product. For example, it is known that 5-exo cyclization of 5-hexynyl radical is slower than the corresponding 5-hexenyl radical cyclization by nearly 10 fold. ${ }^{25}$ Therefore, for xanthate 17, one would expect carbonyl cyclization to be faster than alkyne cyclization. As shown in eq 6 , cyclization of xanthate $\mathbf{1 7}$ gave four isomeric bicyclic alcohols $\mathbf{2 5}$ and $\mathbf{2 6}$ in a combined yield of $68 \% .^{26}$ Monocyclic alcohol 27 was isolated in $10 \%$ yield. The ratio of carbonyl addition products versus alkyne addition products was about $7: 1$.
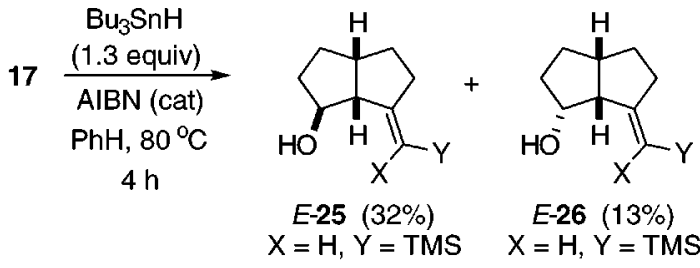

$E-26(13 \%)$

$Z-25(17 \%)$

$X=$ TMS $, Y=H \quad X=T M S, Y=H$

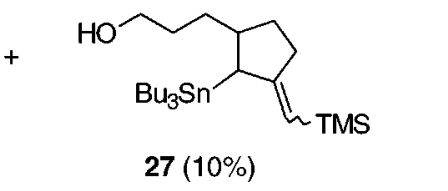

In conclusion, a 1,3-stannyl shift promoted cyclization of an $\alpha$-stannyl radical with a formyl group was developed. This process is successful for 5-exo cyclization. In comparison, the corresponding 6-exo cyclization seriously competes with a 1,5-hydrogen transfer reaction. Approximately, 5-exo cyclizations of an $\alpha$-stannyl radical with a formyl group or with a terminal olefin have similar rates. This information will be useful in the design of tandem cyclizations. However, the reversibility of formyl group cyclization requires further

(19) Curran, D. P.; Liu, H. J. Chem. Soc., Perkin Trans. 1 1994, 13771393.

(20) Hegedus, L. S.; McKearin, J. M. J. Am. Chem. Soc. 1982, 104, 2444-2451.

(21) Beckwith, A. L. J.; Ingold, K. U. Rearrangements in ground and excited states; de Mayo, P., Ed.; Academic Press: New York, 1980; Vol 1 , pp 161-310.

(22) Nagai, M.; Lazor, J.; Wilcox, C. S. J. Org. Chem. 1990, 55, 34403442 .

(23) (a) Beckwith, A. L. J.; Schiesser, C. H. Tetrahedron Lett. 1985 , 26, 373-376. (b) Beckwith, A. L. J.; Schiesser, C. H. Tetrahedron 1985, 41, 3925-3941. (c) Spellmeyer, D. C.; Houk, K. N. J. Org. Chem. 1987, $52,959-974$

(24) (a) RajanBabu, T. V. Acc. Chem. Res. 1991, 24, 139-145. (b) Curran, D. P.; Porter, N. A.; Giese, B. Stereochemistry of Radical Reactions; VCH: New York, 1996; p 57.

(25) Beckwith, A. L. J. Tetrahedron 1981, 37, 3073-3100.

(26) The stereochemistry of these compounds were determined by NOE experiments. 
investigation. In the tandem cyclizations, the $\alpha$-stannyl xanthate moiety serves as a novel $\mathrm{gem}$-diyl equivalent. ${ }^{27}$

Acknowledgment. Financial support by the National Science Council of the Republic of China is gratefully acknowledged.

(27) For the use of gem-dihalide as gem-diyl equivalent, see ref 22.
Supporting Information Available: Synthetic schemes for $\mathbf{1 6}$ and 17. Details of compound characterization of $\mathbf{2 a}, \mathbf{b}$, $\mathbf{4}, \mathbf{1 2}, \mathbf{1 3}, \mathbf{1 5}-\mathbf{2 0}$, and $\mathbf{2 5}-\mathbf{2 7}$. This material is available free of charge via the Internet at http://pubs.acs.org.

OL9901990 